\title{
Primeros elementos para una genealogía del derecho a la ciudad: $\mathrm{H}$. Lefebvre
}

\section{Alfredo Rubio Díaz *}

\section{Resumen}

Han pasado más de cuarenta años desde que, desde una posición original, H. Lefebvre expresó la virtualidad del derecho a la ciudad en un contexto bien distinto del actual en el libro del mismo título publicado en 1968. Una época de auge económico, industrialización y crecimiento urbano, donde aún dominaba la guerra fría con sus conflictos regionales. Desde finales del siglo XX, a pesar de los cambios radicales ocurridos, este trabajo se viene entendiendo como origen de la actual demanda del derecho a la ciudad. Se presenta lo que entendemos como una gramática de lo urbano, compuesta por una serie de nodos que forman la estructura esencial desde la que reflexionar sobre este derecho a partir de aquel trabajo. No se aprecia con claridad una relación directa entre lo que formuló el sociólogo francés y los contenidos actuales que se atribuyen a dicho derecho. En general, $\mathrm{H}$. Lefebvre trató de evitar su formulación positiva que, además, fue pensado para una realidad urbana asentada en un tiempo y un espacio concreto de difícil traslación a cualquiera de las posibles situaciones actuales. En un segundo trabajo mostraremos su concreción actual y sus relaciones con los movimientos sociales recientes.

\section{Palabras clave}

Derecho a la ciudad; Urbano; Urbanismo; Habitar

\section{Abstract: First elements of a genealogy of the right to the city: H. Lefebvre}

It has been more than forty years since, based on an original approach, $\mathrm{H}$. Lefebvre expressed the virtual nature of the right to the city in a very different context from today's in the book of the same title published in 1968. Those were times of a booming economy, industrialization and urban growth, still dominated by the Cold War and its regional conflicts. Since the late 20th century, despite the radical changes that have taken place, this work has been understood as the source of the current demand for the right to the city. The paper presents what the author understands as a grammar of the city, composed of a series of nodes that form the core structure used to analyze the right to the city based on Lefebvre's text. No direct relationship is clearly found between the writings of the French sociologist and the current contents attributed to this right. In general, $\mathrm{H}$. Lefebvre tried to avoid a positive formulation and understood this right in the context of an urban reality existing in a particular time and place that is difficult to translate into any of the possible current situations. A second study will show its current status and its relationship with recent social movements.

\section{Key words}

Right to the City; Urban; Urban Planning; Inhabiting. 


\section{Un encuadre mínimo}

La trayectoria del trabajo intelectual de $\mathrm{H}$. Lefebvre fue y ha sido complicada debido a la confluencia de distintas circunstancias: su contenido original, su confrontación con el marxismo estructuralista, que llegó a ser hegemónico en el campo sociológico, y, más tarde, ya en plena postmodernidad, con la crisis de la razón sociológica. Por todo ello, su influencia no alcanzó la dimensión que cabría esperar. Ha sido constante pero de baja intensidad, lo que no ha impedido su condición de sociólogo de referencia ${ }^{1}$, cuya influencia ha persistido y persiste a través de autores como D. Harvey y E. Soja. En la última década algunas monografías parecen señalar un nuevo interés por algunos contenidos de su obra (Merrifield, 2006, Goonewarde et al., 2006 y Stanek, 2011). Su trabajo significó un incremento real del patrimonio de la Sociología moderna, es decir, supo añadir algo a lo existente $y$, haciéndolo, aportó una gramática nueva relativa a la ciudad, en el borde mismo de la crisis de los años setenta.

Sus contribuciones fundamentales tuvieron casi siempre condición de pioneras tanto en el plano general disciplinario de la sociología como en el particular desenvolvimiento del pensamiento marxista. En términos cronológicos, en primer lugar abrió el campo temático de la vida cotidiana. $\mathrm{H}$. Lefebvre pensaba que tras los análisis quedaba siempre algo: lo que hay de más simple y evidente pero, a la vez, lo más difícil de delimitar y aprehender. Lo informal que desborda las formas (todas las formas). Un aparente residuo: algo pobre, humilde, repetitivo pero que, paradójicamente, es a la vez lo más profundo. La vida cotidiana. Entendía que no hay una vida auténtica que se oponga a otra inauténtica. Ambas se confrontan

1 En Los sociólogos de la ciudad (1979), una obra clásica sobre los principales sociólogos interesados por la ciudad aparecerá junto a M. Weber, K. Marx, F. Engels, G. Simmel, los componentes de la Escuela de Chicago, L. Wirth, R. y H. Lynd y M. Castells (Bettin, 1982). en la vida cotidiana. El descubrimiento de la vida cotidiana implicaba un cambio tanto de los contenidos como del lugar de la acción política: su meta no será ya el cambio del modelo económico, ni siquiera la reivindicación salarial desnuda, tampoco las mejoras en las condiciones de trabajo en la cadena de montaje, estaba en otro lado.

Más tarde, su apuesta por pensar la espacialidad, en un contexto disciplinario e ideológico donde el instrumental era insuficiente para comprender lo resultante de la disolución de la ciudad, dio lugar a la elaboración de una perspectiva teórica donde el espacio fuera objeto central, asociándole múltiples propiedades: sede de las actividades e interacciones del desenvolvimiento social, medio de producción (suelo) y componente de las fuerzas productivas; objeto de consumo, instrumento político y componente de la lucha de clases. Un largo trabajo, un "viaje extraordinario" como lo califica E. So$\mathrm{ja}^{2}$, que finalizará con la vuelta a la vida cotidiana a través del pensar la temporalidad.

Se le considera precursor o antecedente de las organizaciones y movimientos que reclaman hoy este derecho colectivo (Sugranyes, 2010, p. 72). Tales demandas se han especificado en contenidos positivos, cuya principal expresión es la "Carta Mundial por el derecho a la ciudad" (2004-2005), un documento con aspiraciones universalistas. Además, está reflejado en determinadas proposiciones de la UNESCO, en ciertos marcos jurídicos de alcance diverso (constituciones, estatutos de ciudades, cartas de derechos a la ciudad, etcétera), y, sin duda, flota en la atmósfera reivindicativa de los movimientos sociales más recientes.

No pretendemos aquí un análisis de la obra completa del sociólogo francés. Nos circunscribimos casi con exclusividad a una lectura de su Derecho a la ciudad (1968). Considerando el conjunto de

2 Sobre este viaje extraordinario véase Thirdspace. Journeys to Los Angeles and Other Real-and-Imagined Places, 1996, p. 2697. 
su obra dedicada a "lo espacial", este libro parece representar un momento intermedio o preparatorio de La revolución urbana (1970).

\section{El derecho a la ciudad}

\section{La crítica de las disciplinas parcelarias}

La complejidad y los múltiples registros de H. Lefebvre no permiten otra cosa que la desvertebración de su pensamiento si se utiliza la técnica del resumen o de la síntesis. Cosa distinta es poner a la vista, en la medida de lo posible, los nodos fundamentales que lo articulan, sus puntos de partida, sus hipótesis y la potencialidad que queda.

El contexto donde surge el derecho a la ciudad, más una región conceptual que una mera formulación positiva, es una fase expansiva de la industrialización capitalista acompañada del subsiguiente proceso de crecimiento de la urbanización en un país concreto (Francia). Por tanto, su referente no son las condiciones del par pobreza/exclusión en las ciudades del capitalismo de la época sino las estrategias subyacentes tanto en políticas públicas destinadas a resolver la cuestión de la vivienda en términos de los grandes conjuntos como las propias del sector inmobiliario privado.

El epicentro de su crítica se refiere más bien al urbanismo como descubridor del hábitat. Por eso, el concepto central es el de habitar, literalmente frente a hábitat, lo que frecuentemente se olvida al dar cuenta de lo dicho por el sociólogo francés en su momento. Le interesa la vida urbana o, si se quiere, la posibilidad misma de la vida humana (individual y colectiva) en lo urbano tras la disolución de la ciudad. Desde esa perspectiva puso a la vista el conflicto teórico y real entre hábitat y habitar. Dicho de otro modo, el derecho a la ciudad es fundamentado, como veremos, a partir de la crítica del urbanismo funcionalista, como ideología y como práctica. Más tarde, el urbanismo será reconocido como simple práctica ilusoria (Lefebvre,
1972). De ello, que se producirá de acuerdo con las condiciones habituales de su análisis, surgirá todo un tramado conceptual que le permitirá dar cuenta del derecho a la ciudad como un algo atmosférico, más que un listado de contenidos positivos.

Su posición parte de una doble crítica: de las ciencias parcelarias y de la actividad racionalizadora de los burócratas. Esta crítica supone necesariamente la puesta en un primer plano de la filosofía como aspiración a la Totalidad. Más aún, las corrientes que le permiten la construcción de un pensamiento propio proceden precisamente de entender esa aspiración como centro de la reflexión sobre lo urbano. En su opinión, la Filosofía aún no había dicho su última palabra precisamente porque permanece y persiste en esa aspiración. Incluso hacerse la pregunta sobre la ciudad es ya un hecho una posición filosófica. Sin embargo, hay un límite: el concepto filosófico de totalidad puede quedar vacío si sólo es filosófico (Lefebvre, 1969, p. 52).

Su crítica incluye a aquellos pensadores contemporáneos que han reflexionado sobre la ciudad que, más o menos confesadamente, se pretenden filósofos de la ciudad.

"Con este título, estos pensadores quieren inspirar a arquitectos y urbanistas y realizar el vínculo entre las preocupaciones urbanas y el viejo humanismo. Pero estos filósofos quedan cortos de miras. Los filósofos que pretenden «pensar» la ciudad y aportar una filosofía de la ciudad prolongando la filosofía tradicional discurren sobre «la esencia» o sobre la ciudad como «espíritu», como «vida» o «impulso vital», como ser o «todo orgánico». En resumen, unas veces la tratan como sujeto, otras como sistema abstracto" (Lefebvre, 1969, p. 53-54).

De ahí una doble conclusión: en primer lugar, de lo que se trata es de articular la relación filosofía y ciudad. Nunca en los términos de una filosofía de la ciudad. Y, en segundo lugar, esta articulación problemática se concreta en aportaciones desde la 
Filosofía relativas al conocimiento, la formulación de la problemática urbana y la estrategia a concebir. No le atribuye valor operativo alguno (los conceptos filosóficos no tienen nada de operativo) pero su contribución consiste en su entendimiento como unidad de la ciudad, lo urbano y la sociedad entera, "por encima y más allá de fragmentaciones analíticas" propias de las disciplinas parcelarias (Lefebvre, 1969, p. 52).

Se trata de leer correctamente: $H$. Lefebvre no pretende presentar una filosofía de la ciudad sino todo lo contrario, busca refutar esa actitud "devolviendo al conjunto de estas filosofías su lugar en la historia [...]. Nuestro proyecto está en presentar un proyecto de síntesis y de totalidad que la filosofía como tal no puede realizar" (Lefebvre, 1969, p. 45). Por tanto, si bien constata que en la Filosofía hay una tendencia (una aspiración a la totalidad) sabe que no se resuelve. La superación de los análisis mecanicistas que, en su opinión, conducen a un discurso sobre la metaciudad y no sobre la ciudad misma (la ciudad real), la requieren como tensión y como elemento de una confrontación ideológica que incluye desenmascarar la función de las ciencias y, en especial, de las sociales como productoras de ocultación ${ }^{3}$.

Por tanto, abrió un campo donde aparecen los conocimientos parciales que interesan a la ciudad (elementos, funciones, estructuras); las aplicaciones técnicas de esos conocimientos (en un cierto contexto: en el marco fijado por decisiones estratégicas y políticas) y el urbanismo como doctrina/ideología en cuanto que interpreta los conoci-

3 En lo fundamental, $H$. Lefebvre parte del marxismo, depurado de su economicismo, sustentado en ciertas categorías del primer Marx, y lo digo así por razones descriptivas, $y$, sin duda, todo ello se soporta en una raíz dialéctica que algunos entendieron y entienden como hegelianismo $o$ neohegelianismo. Las categorías e instrumentos de su análisis forman triadas o casi triadas: dimensiones materiales, mentales y sociales, entendidas y desarrolladas como niveles en interacción. Una segunda secuencia: función, forma y estructura y tiempo. Su método es regresivo-progresivo: del presente al pasado, producto de su lectura de los "Grundisse", a aplicar a la mayoría de las cuestiones. mientos parciales y justifica las aplicaciones, "elevándolos por extrapolación a una totalidad mal fundada o mal legitimada". En ese sentido, en una clara alusión al estructuralismo, entendía que "las transformaciones de la ciudad no son los resultados pasivos de la globalidad social, de sus modificaciones" (Lefebvre, 1969, p. 64). La condición mediadora de la ciudad exime de cualquier mecanicismo e impone esa actitud que busca la totalidad frente a la fragmentación propia de las disciplinas parcelarias.

\section{Punto de partida: definiciones de ciudad}

Cualquier discurso de la ciudad requiere nociones, conceptos y definiciones como puntos de partida. Este hecho, que se hunde en el pensamiento de H. Lefebvre, contendrá no sólo una crítica de las definiciones formales académicas sino también una superación evidente del vacío conceptual y de los esquematismos dominantes por entonces en el marxismo. Su punto de partida será un entendimiento de la ciudad como especificidad. La ciudad fue (y ha sido) mal considerada: fenómeno (local) reflejo de su reducción como reflejo de algo exterior. Un reflejo local no enuncia una especificidad. Sólo en la actualidad comenzamos "a aprehender la especificidad de la ciudad" (Lefebvre, 1969, p. 63).

En su análisis la ciudad será mediación, lugar de la producción y reproducción de seres (humanos), lugar de producción de relaciones sociales y obras de arte y producto social [histórico]. Su concepción, como veremos, no excluye ninguna posibilidad: cualquier enunciado puede ser dicho. Esa apertura requerirá siempre precisiones suplementarias y complementos.

Ciertamente, la ciudad se puede entender "como proyección de la sociedad sobre el terreno, es decir, no solamente sobre el espacio sensible sino sobre el plano específico percibido y concebido por el pensamiento, que determina la ciudad y lo urbano" (Lefebvre, 1969, p. 75). Pero aquí introdu- 
ce aclaraciones, consciente de ciertas lagunas, que exigen las aludidas "precisiones suplementarias". Lo que se inscribe y se proyecta no es solamente un orden lejano, una globalidad social, un modo de producción, un código general. También se inscribe un tiempo, o mejor aún, tiempos y ritmos. Ambos son claves, generalmente desconsideradas, en el análisis y en el proyecto. Las temporalidades a las que alude y que le interesaban en los últimos años de su quehacer, tratan de la “interacción perpetua” entre la vida cotidiana y los procesos repetitivos ligados al tiempo homogéneo (Lefebvre y Regulier, 1985 y 1992). Por tanto, al introducir las distintas temporalidades y sus consecuentes ritmos está proponiendo una reconsideración radical de la ciudad como organizadora y productora de tiempos. Lo que visualiza son contra-espacios ${ }^{4}$ y contra-tiempos. Lógicamente, ligazón y oposición entre tiempos sujetos a valores de cambio y tiempos vinculados a valores de uso.

Ahí reside la importancia de la fiesta en su análisis, a la que alude recurrentemente. La fiesta es un fenómeno global que remite a un mundo constituido, construido y habitado por los participantes. Un mundo donde éstos celebran la continuidad de sí mismos como relación y vínculo (el nosotros); de aquello que es como lo posible. Poco importa aquí y ahora el origen rural o urbano de la fiesta pues, en nuestra cultura, una vez constituida la ciudad, más aún cuando se trató de la ciudad democrática, la fiesta aparece como institución urbana relevante ${ }^{5}$. La fiesta es una atmósfera, con un tiempo y un espacio, a través del cual la sociedad se reproduce, celebrándose en el marco de una notable ambigüedad. Se pone en cuestión el orden que regula la sociedad o la comunidad por

4 Tomo la expresión del profesor C. Tapia (Universidad de Sevilla).

5 La Fiesta y el juego aparecen como grados de libertad para pensar las fronteras entre lo privado y lo público. Permiten y construye subversiones en los límites entre uno y otro, recuperando ricas relaciones pasadas o inventando nuevas relaciones. un tiempo (limitado, acotado), con sus riesgos, ambivalencias y múltiples posibilidades de ir más allá de la inversión (pautada, acordada en el imaginario colectivo) del orden social si los participantes -o un exterior- no controlan ciertos límites. A la vez, la comunidad -hoy tal vez disuelta- puede encontrarse consigo misma y superar los límites (auto impuesto/impuestos).

Por su parte, los complementos introducen una perspectiva sobre las diferencias históricas y genéricas (genéticas) que obliga a introducir las diferencias actuales entre ciudades (entre los tipos resultantes de la historia, de los efectos de la división del trabajo y entre las relaciones persistentes ciudad-territorio) que autorizan otra definición, que no destruye la primera. La nueva que aportó no deja de parecernos paradójica: "la ciudad como conjunto de diferencias entre ciudades" (Lefebvre, 1968, p. 75). En su momento, el urbanismo urbano entendió que cada ciudad no podía ser otra cosa que el modelo de sí misma (Zarza, 1985).

Pero la posibilidad de una definición no se agota ahí puesto que, si bien se ponen de manifiesto las particularidades, quedan descuidadas las singularidades de la vida urbana (las maneras de vivir en la ciudad), es decir, el habitar propiamente dicho. Este es un asunto decisivo respecto del derecho a la ciudad puesto que obliga a perfilar más adecuadamente sus contenidos positivos.

No es fácil construir una definición universal. Las diferencias existentes entre las ciudades lo impiden, como tendremos ocasión de argumentar más tarde. Aparecen grados muy distintos de artificialidad. A pesar de todo, tal vez sea posible una tipología.

La ciudad es un producto social. Pero hay algo más; produce algo más, que es precisamente aquello que escapa de los planteamientos mecanicistas. Lo que escapa "exige distinguir en la ciudad, como obra de determinados «agentes» históricos, entre acción y resultado, grupo (o grupos) y 
su «producto», lo que no implica su separación. No hay plan sin sucesión regulada de actos y acciones, de decisiones y conductas, sin mensajes y sin código. Sin una materia a modelar, sin una realidad práctico-sensible, sin un espacio, sin una «naturaleza», sin campo y sin medio" (Lefebvre, 1969, p. 67).

La ciudad es obra más próxima a la obra de arte que al simple producto material. Lo es como realización en unas determinadas condiciones históricas. Pero éstas no son suficientes para explicar lo que nació de ellas. Las condiciones permiten y delimitan las posibilidades [las potencialidades], pero, al ser socialmente interpretadas, lo producido estará más allá de las relaciones de causalidad que habitualmente de ponen a la vista. También lo contrario, es decir, suponer que determinados efectos que se han producido en una ciudad podrán ocurrir en otra si se reproducen las condiciones de aquélla.

Lo global siempre es mediado por la ciudad, dicho con más precisión: "la proyección de lo global sobre el terreno y sobre el plano específico de la ciudad solo se efectuó a través de mediaciones. La ciudad es mediación y resultado de mediaciones. En concreto, la lectura de la ciudad requiere el análisis del contexto, no cabe extraer más de lo oportuno de los signos. El contexto sería tanto lo que hay debajo del texto, también lo que hay por encima: las relaciones cotidianas, las relaciones inmediatas, lo «inconsciente» de lo urbano. "Lo que apenas se dice y menos aún se describe, lo que se oculta en los espacios habitados -la vida sexual y familiar- y apenas se manifiesta cara a cara" (Lefebvre, 1969, p. 74). Y lo que hay por encima de ese texto urbano (las instituciones, las ideologías).

Por tanto, la lectura del libro que compone el texto de la ciudad no basta. Hay suficientes elementos por debajo y por encima que deben ser aclarados. $H$. Lefebvre sugiere una lectura crítica, aquella que se compone de preguntas: ¿Quién y qué? ¿Cómo? ¿Para qué? "Estas preguntas anuncian y exigen la restitución del contexto. La ciudad no puede concebirse como un sistema significativo determinado y ensimismado en cuanto a sistema" (Lefebvre, 1969, p. 74).

Pero lo global -en el texto se dice la globalización social- no crea o impulsa el cambio de la ciudad a partir de su pasividad [de un estado de pasividad de la ciudad]. La ciudad depende, y no menos esencialmente, de relaciones inmediatas, de vinculaciones directas entre personas y grupos que componen la sociedad (familias, cuerpos organizados, oficios, corporaciones, etcétera). Si bien la ciudad organiza estas relaciones, se sitúa en un "punto medio" entre el orden próximo y el orden lejano ${ }^{6}$.

Definiciones relativas a niveles de la realidad social que no pretenden ser exhaustivas ni excluyen otras posibles. Por ejemplo, si la ciudad se piensa como lugar de confrontaciones entre deseo y necesidad cabría su inclusión; también se puede poner el acento en su papel histórico como aceleradora de procesos, el cambio, el mercado, la acumulación de conocimientos y de capitales; como lugar de la revolución y de la intensificación de la explotación de la sociedad entera; como lugar de los centros de decisión, etcétera.

La ciudad escapará como objeto, como si careciera de límites y no admitiera delimitación alguna. Huye del acotamiento preciso de las disciplinas parcelarias. Por tanto, lo que presenta es un algo abierto cuya accesibilidad teórica y real se precisará más tarde con las dimensiones y niveles, una

6 Esta argumentación tiene hoy un notable interés. No todo se explica por la pura apelación a las consecuencias de la globalización, como viene siendo habitual. Los flujos de todo tipo son leídos e interpretados (reflexionados) por grupos concretos (Chaline, 1981). La simple adaptación sería una forma de pasividad que niega tanto los procesos reales de intermediación como la posibilidad de la creatividad social. Por el contrario, ciertos autores han insistido en la realidad de un doble movimiento de lo global a lo local y viceversa que rompe con los planteamientos habituales, las iniciativas locales pueden infiltrarse hacia arriba, hacia una escala global $y$ viceversa (Harvey, 2005). 
estratigrafía cuyos componentes están en interacción (Lefebvre, 1972)

\section{El urbanismo y su crítica}

Muchas veces se parte de pensar la ciudad moderna según el modelo de la ciudad antigua. Todos los filósofos actúan mediante un mismo operativo que supone el salto desde los conocimientos parciales a la totalidad. Como Le Corbusier, que se comporta como un filósofo cuando "describe la relación del habitante y del habitante urbano con la naturaleza, con el aire, el sol y el árbol, con el tiempo cíclico y los ritmos del cosmos" (Lefebvre, 1969 , p. 60). A esta visión ideológica añade conocimientos parciales ciertos sobre los problemas reales de la ciudad pero, con todo, "el funcionalismo reduce así la sociedad urbana a la ejecución de algunas funciones previstas y prescritas sobre el terreno por la arquitectura. Semejante arquitecto se considera «hombre de síntesis», pensador y practicante. Cree y quiere crear las relaciones humanas definiéndolas, concibiendo su marco y su ambientación. El Arquitecto, en una perspectiva que toma como punto de referencia horizontes bien conocidos por el pensamiento, se percibe y concibe como Arquitecto del Mundo, imagen humana de Dios creador" (Lefebvre, 1969, p. 60).

El urbanismo en cuanto que interpreta los conocimientos parciales y justifica las aplicaciones, "elevándolos por extrapolación a una totalidad mal fundada o mal legitimada" es una doctrina/ideología. De ello no se debe concluir que no haya recibido formulaciones cada vez más precisas. Estudiar los problemas de circulación, de transmisión de órdenes en la gran ciudad moderna, conduce a conocimientos reales y técnicas de aplicación.

"Declarar que la ciudad se define como red de circulación y comunicación, como centro de informaciones y decisiones, es una ideología absoluta; esta ideología procedente de una reducciónextrapolación particularmente arbitraria y peligrosa se presenta como verdad total y dogma, utilizando medios terroristas. Conduce al urbanismo de tuberías y viales, y cálculos que se pretenden imponer en nombre de la ciencia y el rigor científico, cuando no por medios peores" (Lefebvre, 1969, p. 61).

El urbanismo como ideología se sustenta en dos aspectos: por una parte, implica una teoría de la racionalidad y la organización, cuya aparición se sitúa que en torno a finales de la primera década del siglo $X X$. Por otra, reducirá todo al uso de la noción de espacio, relegando al olvido el tiempo y el devenir, y transpone en términos espaciales todo lo que viene de la historia, de la conciencia. Puesto que la sociedad no funciona de un modo satisfactorio se sugiere "una patología del espacio" (Lefebvre, 1969, p. 61). Dicha patología tiene una etiología y define su propio índice "como un síntoma entre otros que engendra enfermedades sociales". Los problemas no procederán de la constitución misma de cada sociedad sino de esa espacialidad, lo que permite diseccionar el propio espacio de modo que el urbanista sabrá distinguir los espacios enfermos de los espacios vinculados a la salud mental y social, generadores de esta salud. Médico del espacio, tendría capacidad para concebir un espacio social armonioso, normal y normalizante. Su función se reduciría por tanto a "acordar a este espacio (que se encuentra como por azar identificado al espacio de los geómetras, al de las topologías abstractas) las realidades sociales preexistentes" (Lefebvre, 1969, p. 61-62).

Por otra parte, aparentemente la reflexión urbanística parece reactivarse y renovarse en los periodos de crisis (Lefebvre, 1969, p. 75). Pero no es exactamente reflexión ese cambio de registro que permite a la urbanística manifestarse en cada período de acuerdo con su fría objetividad. Dirá una cosa y la contraria en cada uno de esos períodos sucesivos. Lo entiende como mutación, como síntoma de mutación. Una pura inquietud que se presenta ideológicamente como racionalidad (Lefebvre, 
1969, p. 75).

Lo que propone es la crítica rigurosa del urbanismo ideológico tanto en el plano teórico como en el práctico. Y aclara: todo ello "no puede darse sin largas investigaciones, sin estudio paciente de los textos y los contextos" (Lefebvre, 1969, p. 62). Probablemente muchas de sus conclusiones no procedían de un conocimiento preciso de la historia real de las prácticas urbanísticas, consecuencia de la escasa investigación existente en su época. Más tarde, con mayores precisiones, $\mathrm{H}$. Lefebvre mantendrá esta caracterización pero, sobre todo, incluirá la idea de su actividad como práctica ilusoria incapaz de controlar las tendencias internas del capitalismo. Lo que diferencia al capitalismo de otros modos de producción es la producción y reproducción peculiares de un "desarrollo" geográficamente desigual, con tendencias simultáneas hacia la homogeneización, la fragmentación y la jerarquización, de alcance global.

\section{La concreción del derecho a la ciudad}

Mientras que la reflexión quedaba reducida por entonces al repertorio de las formas, las funciones y estructuras de las ciudades, las necesidades (sociales) inherentes a la sociedad urbana quedaban relegadas y no se investigaban -se está refiriendo a la Francia de fines de los años sesenta del pasado siglo. Por el contrario, las necesidades individuales sí lo eran, justamente para ser manipuladas. Para H. Lefebvre el derecho a la ciudad implica el conocimiento de las necesidades sociales. Sin embargo, no cabe el listado "perfecto" de éstas. Las necesidades tienen una naturaleza dual opuestas y complementarias a la vez. Incluso hay necesidades que no se resuelven en los equipamientos comerciales y culturales (Lefebvre, 1969, p. 123).

Hay una renuncia a ser taxativo pero, a pesar de todo, $\mathrm{H}$. Lefebvre no concebirá el derecho a la ciudad como aquello que comprende la formulación de una constelación de contenidos positivos relativos a la satisfacción de ciertas demandas.

Se refiere a la actividad creadora como derecho, diríamos que matricial, acompañada de los derechos a la información, el simbolismo y las actividades lúdicas. Estos derechos se especifican en la demanda de lugares cualificados, aquellos que permiten la simultaneidad y el encuentro. Probablemente contra-espacios respecto de los impuros no lugares descritos por M. Augé, es decir, lugares de superación del anonimato, inscrito en lo contractual de los no-lugares, que permitan aflorar el vínculo social y la creatividad. Lugares para las relaciones cercanos a los que demanda U. Beck, producto de una arquitectura reflexiva capaz de producir lugares de acogimiento. Claro es, la demanda de lugares para el capital relacional significan la inclusión del tiempo. Inmateriales que no guardan o tienen relación alguna con los valores de cambio. En síntesis, lo que propone y demanda no es mejorar lo existente sino transformarlo.

Muerta la ciudad, producto del proceso capitalista, emerge lo urbano que no es un residuo, sino un potencial para la construcción social de la espacialidad de lo urbano sobre nuevas bases, es decir, "en otra escala, en otras condiciones, en otra sociedad" (Lefebvre, 1969, p. 125). Pero esas condiciones no pueden ser producidas desde formas y decretos puesto que las relaciones sociales no pueden crearse desde un afuera, menos aún podrán crearlas un sociólogo, un arquitecto, un médico. Únicamente la vida social (la praxis) en su capacidad global posee en su opinión ese poder de creación y una teórica ciencia de la ciudad queda reducida a la investigación, la emisión a la vista de proposiciones y el ensayo. Una transformación de los procederes y de los instrumentos intelectuales para dar lugar a la proposición de modelos abiertos.

Por tanto, tras una proposición no taxativa (espacios y tiempos cualificados), vuelve a insistir en la 
problemática de una ciencia analítica de la ciudad, de lo que sólo se podría hablar en términos de esbozo. Si hay conceptos sólo se avanzará a partir del quehacer (hacer y deshacer) de lo social; con una realidad urbana en elaboración que exige olvidar la ciudad antigua (la nostalgia de una ciudad que se supone existió). Pero ese objeto no está dado, el pensamiento estudia simplemente un objeto virtual y ello impone procederes nuevos (Lefebvre, 1969, p. 125).

En consecuencia, el conocimiento podrá elaborar modelos y proponerlos pero "semejante «realidad» nunca podrá ser manejada como cosa, nunca adquirirá rango instrumental. Ni siquiera para el más operativo conocimiento" (Lefebvre, 1969, p. 132). La transformación -dar cuenta de lo urbano y ponerlo en marcha- requiere una estrategia (urbana), de la que carecemos. Su posibilidad sólo será efectiva si determinados grupos, clases y fracciones asumen conjuntamente ese esfuerzo.

De donde esa actividad es política y la ciudad nueva sólo será posible a través de dichas fuerzas sociales. Esa actividad política tiene en primer lugar el trabajo de deshacer las estrategias y las ideologías dominantes en la sociedad actual. $\mathrm{H}$. Lefebvre no podía concebir otro sujeto de esa actividad que la clase obrera, aún presente en la industrializada Francia de la época. Dicha clase no será sólo factor motriz de la emergencia de lo urbano. "Sólo esa clase en cuanto tal puede contribuir decisivamente a la reconstrucción de la centralidad destruida por la estrategia de la segregación y reencontrada bajo la amenazadora forma de los «centros de decisión»" (Lefebvre, 1969, p. 133). No es que no puedan darse en ese proceso la presencia de otros grupos con idénticos objetivos pero sin ella nada será posible.

\section{De entonces a hoy}

\section{Tendencias y diagnósticos de la realidad social: el liberalismo existencial}

Desde entonces los cambios han sido no sólo profundos sino acumulados y probablemente con una mayor rapidez que en cualquier otro periodo histórico. Muchas de estas mutaciones, que han afectado profundamente a la sociedad, provienen del cambio económico y de su base productiva; del tecnológico, que ha permitido nuevas pautas de localización industrial y la emergencia y consolidación de la sociedad de la comunicación, induciendo nuevas formas de producción, de relaciones laborales y sociales; de las transformaciones internas del sistema capitalista, con la hegemonía del capitalismo financiero, desgajado de cualquier base productiva, y la paralela de la sociedad de consumo. También debe consignarse la entrada en escena de nuevos campos de gran trascendencia, tales como la crisis social urbana que se deriva de la constatación generalizada de la ausencia de cohesión social y la emergencia de la preocupación por las cuestiones medioambientales, es decir, de la necesidad de poner freno a la depredación de los ecosistemas.

La paulatina construcción, desde las primeras experiencias del siglo XIX, de mecanismos dispositivos e instituciones capaces de contemporizar las tendencias destructivas más radicales del capitalismo, consolidadas tras la II Guerra Mundial, permitieron dar forma y continuidad a poderosos sistemas de bienestar, que comenzaron su declive en los años setenta del siglo $X X$, en una tendencia que no sólo perdura sino que se ha radicalizado en los últimos años. En la actualidad el capitalismo apela a la desregulación y sitúa el mercado como un trascendental que no admite limitaciones de ninguna naturaleza mientras que extiende el consumo hasta convertirlo en forma y razón de vida que se antepone a cualquier otra posibilidad. 
Las lecturas de los sociólogos de este proceso son diversas. Antes de enunciarlas someramente debemos considerar el propio cambio disciplinar. Desde los primeros años sesenta, la mayoría de los teóricos sociales coincidieron en que la denominada "sociedad industrial desarrollada" iba adoptando unos rasgos que la diferenciaban de la sociedad industrial clásica. Sin embargo, no existió acuerdo sobre el diagnóstico de las causalidades que debían considerarse decisivas. Se apelaba a la terciarización de la sociedad y los nuevos sectores productivos (R. Dahrendorf, D. Bell y A. Touraine); se daba prioridad a las consecuencias sociales derivadas de los impactos de las denominadas nuevas tecnologías $(\mathrm{H}$. Coleman) o se formulaban diagnósticos más complejos proporcionados por algunos de los teóricos de la postmodernidad. Las distintas interpretaciones ponían un elevado énfasis en la descripción de los procesos de cambio, al menos de algunos de sus componentes, más que en la definición de propuestas de pautas interpretativas y contenidos de nuevo cuño. En ese contexto, que $\mathrm{H}$. Lefebvre hubiera calificado de campo ciego, las dos grandes corrientes sistemáticas del análisis social, las distintas tendencias sociológicas funcionalistas y marxistas, perdieron su papel hegemónico, dando lugar a la multiplicidad de paradigmas y de referencias teóricas actuales. Se produjo una yuxtaposición de orientaciones y de trabajos extremadamente dispares en un contexto donde los grandes sistemas explicativos carecían de capacidad para imponerse como relatos ciertos acerca de lo social. En tal situación, a fines de los años ochenta, se consolidaron ciertos intentos por conseguir una salida a la crisis teórica, etiquetados como constructivismo (Corcuff, 1968) ${ }^{7}$.

Por constructivismo debe entenderse más bien

7 Las trayectorias y los intereses del grupo de sociólogos considerados constructivistas (N. Elias, P. Bordieu, A. Gidens, P Berger, T. Luckmann, E. Goffman, entre otros) no eran coincidentes pero constituyeron y dieron forma a la salida parcial de la crisis disciplinaria a que se alude. una problemática, un conjunto de problemas e interrogaciones que forman parte de la salida de la crisis teórica de los años setenta, que una corriente coherente. Para sus componentes "las realidades sociales se conciben como construcciones históricas y cotidianas de actores individuales y colectivos" (Corcuff, 1968, p. 19) Por tanto, la realidad social es resultado de construcciones de elaboraciones anteriores y procesos en curso de construcción. Esto significaba la recuperación del tiempo histórico y, por tanto, una superación con respecto al estructuralismo dominante durante la década de los setenta.

En ese mismo contexto, algunos sociólogos, notablemente separados por sus presupuestos y enfoques de las cuestiones sociológicas, coincidieron siguiendo caminos distintos en una noción sobre la condición de la sociedad actual: su caracterización como lugar de riesgo ${ }^{8}$. Entienden que, en los países centrales, los cambios sociales se han producido como acentuación de los procesos de individuación, que disuelven y disgregan la relación individuo-sociedad y crean las condiciones para la disolución de lo social, caracterizada por el binomio individualización/estrechamiento de las redes sociales de pertenencia (no virtuales), se especifica en una nueva incertidumbre (ontológica) ( $U$. Beck). El consenso sobre el objetivo de un equilibrio social basado en el bienestar colectivo ha sido sustituido por una atmósfera insolidaria que rompe con la cohesión social al acentuar el contenido ais-

8 El concepto de sociedad del riesgo fue aportado por V. Beck (1986). Tiene múltiples registros. Entre sus significaciones, la idea de la imposibilidad de conocer los impactos derivados de las opciones puestas en práctica y, a la vez, del problema de su imputación, dados los múltiples centros de decisión presentes. Con esta expresión, U. Beck, creador del concepto, se refería a un estadio de desarrollo en el que los pilares de la organización social no descansan ya sólo, como había venido aconteciendo hasta la fecha, sobre la administración y la distribución desigual de los recursos, sino, fundamentalmente, sobre la distribución más o menos consensuada, de aquellas consecuencias, poco o nada anticipables, que se derivan de la toma de decisiones de relevancia pública (Rodríguez Ibáñez, 1993, p. 8). Por tanto, en ámbitos como la economía, la administración de la energía, las aplicaciones de las tecnologías, no existe capacidad alguna de tomar decisiones con certeza respecto de sus consecuencias. De igual modo, el conocimiento, el diagnóstico y la dirección de los cambios sociales se torna imprevisible. 
lado y autogobernado de las biografías personales.

Por su parte, tendencias más recientes inciden en acentuar tanto las causas como el resultado social. Han acuñado la expresión "liberalismo existencial" cuya metáfora sería la figura del "Bloom"” capaz dar cuenta de la experiencia vital del hombre contemporáneo: la extrañeza consigo mismo ${ }^{10}$. Veamos: se construye un imaginario colectivo y otro individual, éste último tiene evidentes relaciones con el primero pero no lo comprende en su totalidad. De ser así, no cabría la diferenciación actuante en la realidad. En ese esquema, el imaginario construido deviene en mi propia exaltación, es decir, en la trascendencia que adquiere para mí propia individualidad. Objeto y objetivo de mis preocupaciones y ocupaciones. Todo parece hecho para que el ser humano se relacione solamente consigo mismo. Se atribuye al Bloom "una nueva filosofía de la existencia" y se considera que las técnicas del capitalismo son las causantes de las transformaciones:

"las técnicas políticas del capitalismo consisten, sobre todo, en destruir los lazos mediante los que un grupo encuentra los medios de producir, en un mismo movimiento, tanto las condiciones de su

9 U. Beck se refiere claramente al proceso por el cual el individuo ha sido vuelto responsable de su biografía. Esta se torna su posesión [única]. Una posesión -la de su vida, la de su biografía- que es de su exclusiva responsabilidad, de donde se deducen sus múltiples y hondas repercusiones sociales. En realidad no hay nada nuevo, salvo el énfasis. Recuérdese: la extranjería del habitante metropolitano, como condición primera de la metrópolis, de G. Simmel; la sociabilidad en las grandes ciudades de la Escuela de Chicago, la individuación de $\mathrm{U}$. Beck; el otro como problema de G. Lipovetsky, el individualismo de masas de Sloterdijk o la estética del socius de las tribus urbanas de M. Maffesolí entre otros muchos. Por su parte, el colectivo Tiqqum afirma que, desde hace treinta años, triunfa el liberalismo existencial. Lo define como "el hecho de que se admita en lo sucesivo como natural una relación con el mundo basada en la idea según la cual cada uno tiene su vida" (Llamamiento y otros.., 2009, 45).

10 El contexto de la "Teoría del Bloom" (Tiqqum, 2000) es justamente el proceso mismo del pensamiento crítico europeo, largo y extenuante. Apenas abordable e inacabado justamente por inacabable (la teoría no tiene fin, tampoco finalidad aparente). En dicha teoría se entrecruzan las referencias a B. Spinoza y M. Heideggerr; G. Debord y G. Agamben. Se entretejen relaciones entre G. Deleuze y B. Spinoza y, por tanto, con Paolo Virno (éxodo, inteligencia colectiva y multitud), y T. Negri y Michel Hardt (biopolítica, imperio y multitud). subsistencia como las de su existencia. Es decir, separar las comunidades humanas de la infinidad de cosas, piedras y metales, plantas, árboles de mil usos, dioses djins, animales salvajes o domésticos, medicinas y sustancias psicoactivas, amuletos, máquinas y todo el resto de seres en compañía de los cuales los seres humanos constituyen mundos" (Tiqqum, 2009, p. 52).

El capitalismo declara obsoleto todo aquello que va a destruir, también cuando afirma la puesta en valor de algo, que será destruido en su ser. Este proceso de desecación progresiva tiene su sede fundamental en las metrópolis que son "punto de concentración máxima de esas técnicas políticas del capitalismo" (Tiqqum, 2009, p. 53).

Otra línea de investigación ha tratado de reflejar el sentido del cambio social como superación de la racionalidad instrumental y la adopción de otra dirección (Inglehart, 1999, p. 17). Se refiere a la acentuación de las tendencias postmaterialistas. Estas surgen exclusivamente en contextos de certidumbre, fundamentalmente en aquellas sociedades que han cubierto las etapas de industrialización y urbanización. El postmaterialismo no puede ser asociado ni a no materialismo ni a antimaterialismo. El contenido nuclear del concepto se refiere a un cambio en las prioridades sociales en el sentido de una profundización de aquellas relacionadas con la autoexpresión y la calidad de vida ( $R$. Inglehart) ${ }^{11}$. Las actitudes postmaterialistas serían la más exacta expresión o manifestación en la sociedad de la postmodernidad. Sin embargo, tienen en consideración que tal cambio puede experimentar una regresión, una vuelta a las prioridades materialistas, como consecuencia de un colapso de la seguridad.

En todo caso, se perfila una sociedad debilitada

11 El término postmaterialismo, creado por R. Inglehart, sólidamente anclado en la investigación empírica, denota un cambio de metas a las que la gente da importancia después de haber alcanzado una seguridad material, y porque ha alcanzado esa seguridad material. No hay inversión de polaridades, sino un cambio de prioridades, se da prioridad a la autoexpresión y la calidad de vida" (Inglehart,1999, p. 45). 
cuando no inexistente que, a su vez, se ve literalmente encapsulada por la creación de sentido desde los medios: se ha hablado de un entorno fantaseado por los grandes medios de información y persuasión. Los medios de comunicación como monopolio autónomo de la producción de sentido. Definen lo visible en un modo de desenvolvimiento particular donde lo esencial consiste en conferir al estado de cosas en vigor una inquebrantable objetividad (verdades científicas objetivas) y por generar una visión del mundo fundado sobre el postulado del asentimiento de lo que es.

Respecto de H. Lefebvre, no pudo prever todos los contenidos de la evolución social; resulta evidente que, como veremos, consideró a la clase obrera como potencial creadora y articuladora de las estrategias adecuadas para la emergencia de lo urbano. Hoy, al menos en los países centrales, dicha clase ha quedado fragmentada, diluida o literalmente desaparecida. Sin embargo, se acercó a la situación actual a través del concepto de mistificación. Lo entendía como procedimiento generalizado de inversión de la realidad. Su análisis deriva de una más que atenta lectura y reelaboración de la alienación como "rapport" del hombre en el mundo. En él confluyen tanto Hegel como el "joven" Marx: la conciencia individual no se explica por ella misma; no hay conciencia en sí. En la sociedad burguesa el individuo se cree "familiar" consigo mismo; se concibe a sí mismo como "su bien y su propiedad" y cuando esa conciencia se rompe o desecha el individuo llega a la angustiosa conciencia "malhereuse" de Hegel al descubrir la distancia que le separa de sí mismo. A partir de la teoría marxista del fetichismo se da a la luz una idea clave: la alienación no es sólo económica, actúa en todos los ámbitos de la vida. Estamos en un campo, como veremos seguidamente, de confluencias, sin que esté claro si nos encontramos ante préstamos o ante trayectorias paralelas que iban abriendo el campo de lo cotidiano. En concre- to, se atisba un trabajo paralelo al de Lukács, se prefigura la dialéctica negativa de T. Adorno y ciertas relaciones, acaso cruzadas, respecto del concepto de alltäglichkeit, usado por Lukács y de clara presencia en M. Heidegger, que lo emplea para reflejar la existencia inauténtica del Dasein.

\section{Cambios en las ciudades y territorios de lo urbano}

La hipótesis de $\mathrm{H}$. Lefebvre parece confirmada: la disolución de la ciudad se ha producido, no es un acontecimiento por venir. Lo urbano pugna por ser constituido. Desde la publicación del libro que analizamos las transformaciones han sido exhaustivas. A la acentuación de las dinámicas de crecimiento generalizado y de expansión de la urbanización, apoyadas en las disponibilidades tecnológicas, han venido a sumarse nuevas bases económicas con la pérdida de las industriales, siempre refiriéndonos a la situación en los países centrales.

Han cambiado la escala y la configuración de las ciudades. En el plano físico, ha desaparecido la ciudad compacta, sustituida por tejidos discontinuos que colonizan los territorios rurales y engloban otras ciudades y núcleos de población. El predominio de lo urbano ha transformado todo en una cuestión territorial. Dominan y se generalizan los procesos de metropolitanización ${ }^{12}$.

Se han generado dinámicas que dan como resultado intensos procesos de reestructuración o remodelación geográficamente articuladas (D. Harvey). En la intraciudad dominan los procesos de tematización y especialización funcional específi-

\footnotetext{
12 "Probablemente es en los procesos metropolitanos donde de forma más clara y extendida, en lo que respecta a las sociedades modernas, se manifiesta la nueva condición de lo urbano y la auténtica escala y organización de la ciudad real contemporánea, dando lugar a procesos y estructuras espaciales relativamente complejos, que dependen tanto de las características singulares que cada realidad urbana posee territorial, histórica, etc.- como de la intensidad y alcance de tales procesos, pero que en cualquier caso ofrecen como resultado la aparición generalizada de una nueva forma urbana claramente diferenciada de la ciudad tradicional compacta" (Feria, 2011, p. 13).
} 
cos, con sentidos diversos, y emergen las intraperiferias. El anhelo modernista por el progreso y la planificación territorial han dado lugar a intentos por enfrentarse a la ciudad a través del diseño de fragmentos que, a menudo, abarcaban narrativas locales y arquitecturas al gusto del consumidor. A este respecto, se considera que el espacio da forma al objetivo social, por la importancia dada a la estética (Cooke, 1990). Sus consecuencias serán las ciudades como paisajes fracturados en enclaves protegidos, rodeados de áreas fuertemente vigiladas ocupadas por los pobres y marginados. Una combinatoria entre el lujo y "una matriz de miseria empobrecida".

El auge de la ideología de la seguridad también se expresa en la huida a las urbanizaciones de interés común, las UIC, donde cristaliza el hogar fortificado $^{13}$. En todas partes proliferan las comunidades cerradas (gated communities) en las que domina la lógica de la seguridad respecto del exterior y las normas de los sindicatos de propietarios en el interior.

Por tanto, también se acentúa el papel de la seguridad como lógica de lo extraurbano, no sólo en términos de vigilancia y control, sino también como comunidades de los socialmente iguales donde aumenta el grado de certidumbre. Se ha argumentado que, "herméticos e introvertidos, esos espacios privados dirigen a la ciudad un rechazo categórico" (Bégout, 2007, p. 43). Pero esta afirmación exige matices: se acentúa un movimiento contradictorio de huida y reafirmación de la ciudad. Como se ha dicho, ha surgido una fenomenología que hace tan sólo unas pocas décadas hubiera sido considerada poco menos que imposible por contradictoria: se huye de la ciudad (crecen los suburbios) y, a la vez, se reafirma la ciudad como

13 Utilizo el fenómeno de las UIC como metáfora significativa de los procesos generalizados de huida de aquellos segmentos sociales que tienen la capacidad real de elegir un emplazamiento, consciente de las diferencias que pueden darse, según países, respecto del patrón norteamericano original. "centro de luces y atracciones". De esa manera, el escenario actual confirma y desmiente simultáneamente las dos tendencias: la huida y la vuelta de determinados segmentos sociales (Améndola, 2000).

Las aludidas transformaciones tienen un evidente correlato en los nuevos patrones territoriales, con grados de complejidad distintos y susceptibles de ser objeto de tipologías. Desde los pasados años noventa, el concepto de red se convierte en central para definir cualitativamente el territorio. En tales texturas las "ciudades" son nodos de circuitos internacionales del capital y de la cultura, que están reemplazando a los lugares locales. Se genera un universo genérico que reemplaza la anomalía y el encanto de los lugares locales por un universo particular (homologado y homogéneo). Sin embargo, a pesar de que sea posible dar cuenta de pautas y hasta de patrones, no parece posible definir otra cosa que una multitud de situaciones bien distintas; de pautas y tendencias que convierten cualquier generalización en abusiva.

Las ciudades se van conformando físicamente como territorios de ruptura con el sentido (social), consecuencia de la combinatoria del par crecimiento demográfico/crecimiento físico discontinuo bajo los efectos territoriales y sociales del neoliberalismo. En cuyo interior proliferan "estilos de vida" incomunicados e incomprensibles entre sí que, a su vez, transcurren sobre texturas físicas desiguales (sedes distintas). Surgen y proliferan los espacios acotados y aislados que ponen en duda la existencia real y efectiva de la ciudad como totalidad perceptible y hacen imposible cualquier idea o sentimiento (social) de (co)pertenencia.

En general, estos procesos de cambio han sido evaluados no sólo como necesarios sino como inevitables. En la mayoría de las ocasiones la ciudad, apelativo puramente metafórico, debe adaptarse a unas nuevas condiciones mediante la acentuación de una supuesta capacidad reflexiva 
y adoptando ciertas cualidades para atraer flujos de toda naturaleza. Por tanto, también debe adquirir una doble condición: de sujeto y de producto. Sólo ocasionalmente la bibliografía especializada definía límites o señalaba disfunciones, sin poner nunca en tela de juicio los presupuestos, las estrategias y, en definitiva, el motor efectivo del proceso. Sin embargo, en los últimos años han comenzado a emerger investigaciones y trabajos colectivos que expresan el malestar ocasionado por la naturaleza de tales procesos de reestructuración y sus consecuencias ${ }^{14}$.

\section{Conclusiones: la gramática urbana de H. Lefebvre y el derecho a la ciudad}

Parece claro que el objeto de reflexión de $\mathrm{H}$. Lefebvre no era una ciudad abstracta sin tiempo ni lugar. No es abusivo entenderla fundamentalmente como la ciudad europea, singularmente la francesa, en un contexto donde la industrialización estaba muy presente, y no se atisbaban los procesos que la afectaron radicalmente desde los años setenta del pasado siglo XX. Por tanto, hoy la situación es bien distinta y sus claves son la "ciudad" desindustrializada, fragmentada, cercada, extendida y habitada por seres individualizados, extremadamente distantes entre sí. Profundamente artificial, asentada en una base tecnológica que $\mathrm{H}$. Lefebvre no pudo intuir, y con problemas de naturaleza distinta de la meras demandas y disfunciones infraestructurales.

En su origen el enunciado "derecho a la ciudad" se localiza más allá de los déficits en infraestructuras, equipamientos y servicios. No se trataba de argumentar sobre determinados derechos que ya estaban sancionados positivamente en el marco del "estado del bienestar" sino sobre aquellos deducibles de las potencialidades que emergían de lo urbano. Se tiene la impresión de que no se alude a

14 En el caso español sobresalen los análisis de ciudades como Barcelona, Madrid, Bilbao, Sevilla y Málaga, que analizaremos en la continuación de este trabajo. la resolución de un cierto conjunto de necesidades (vivienda, infraestructuras, alimentación, saneamiento, agua, ambiente saludable, movilidad, accesibilidad, etcétera) sino a la construcción de lo urbano a partir de las ciudades europeas. Por tanto, en mi opinión, no es fácil su traslación a otras realidades donde tales demandas son objetivas.

En el plano de lo urbano se trata ahora de hacer emerger los espacios necesarios para una "sociedad" constituida por individualizados. Aun teniendo en cuenta los límites de su análisis histórico del urbanismo, una parte de sus conclusiones parecen similares a las de $U$. Beck cuando confirmaba el territorio como única sede donde es posible la (co)producción social de identidad: "vida privada, espacio privado: esta es la fórmula que determinó esencialmente nuestra arquitectura de postguerra [...]. Ahora bien el espacio propio no crea identidad social, ni tan siquiera una personal. La identidad surge de los espacios intermedios tan castigados por la arquitectura, del dominio público, del barrio, incluso para la conciencia privada" (Beck, 2000, p. 117-118). Ambos se refieren al concepto de construcción comunitaria (espacios acogedores) ${ }^{15}$, capaz de actuar como lugar de la identidad individual y colectiva, donde la primera no elimina la posibilidad de la segunda.

Aunque las alusiones a los procesos de segregación espacial no son habituales en el texto se deduce, y se acentuará en La revolución urbana, el derecho a la centralidad de los ciudadanos. Actualmente la coherencia (social), es decir, la necesaria referencia a una globalidad, ya no es posible deducirla o percibirla directamente por los ciudadanos, se consigue a través de "las terminales de anuncios a domicilio" y la sustitución de la ciudad por ciertos fragmentos recualificados e iconizados que desempeñan el papel de imagen global urbana (por ejemplo, determinados hitos, el centro his-

15 La distinción entre espacio acogedor y espacio contenedor nos parece relevante y sugerente. 
tórico, una determinada y supuesta cualidad, etcétera). Cuando planteaba el derecho a la centralidad se estaba refiriendo al reinado efectivo de una alta densidad semántica en todos los espacios de la ciudad, acaso parcialmente asimilable con el derecho a lo bello.

La espacialidad, una de las principales aportaciones de $\mathrm{H}$. Lefebvre, ha adquirido carta de naturaleza como elemento clave en el análisis social y la teoría urbana. Existe un acuerdo (teórico) generalizado sobre que la actividad social no es posible sin un suelo (una sede). No ha sucedido lo mismo con la temporalidad. Justamente en las enumeraciones de lo que hoy pudiera ser el derecho a la ciudad debiera ser más que sobresaliente la consideración del tiempo como núcleo matricial de los derechos urbanos.

La aceleración improductiva atraviesa la vida cotidiana de los ciudadanos (Innerarity, 2009). Por esa razón, de las temporalidades que apunta $H$. Lefevbre, la única opción reside en la posibilidad de la introducción del tiempo lento como horizonte posible, como barajan ciertos movimientos (la slow city). No es este un asunto filosófico, implica la consideración del tiempo -o de los tiempos- como un asunto político. Lo que se deduce es el horizonte posible de una vida cotidiana no atravesada por el tiempo abstracto, acogedora de la duración e impregnada de serenidad.

Tampoco encontraremos una concreción de lo que el habitar pudiera ser como respuesta a las condiciones del hábitat (funcionalista). En lo urbano, el concepto de habitar se resuelve en la idea del habitar poético, aludido en La revolución urbana (1970), y que es posible complementar con su Manifiesto Diferencialista (1970). Por una parte, el derecho a la diferencia y, singularmente, el entendimiento del desarrollo precisamente como creación de diferencias, en abierta oposición al binomio homogeneización/homologación presente en las metrópolis (genéricas) y, por otra, el habitar en términos de coexistencia con las cosas, los otros y la naturaleza (M. Heidegger). Todo ello supone una nueva racionalidad, otros valores e, incluso, la invención de la vivienda como lugar donde sea posible esa actitud poetizante en lo privado. Por tanto, se trata de construir una estela de lugares habitables en las distintas escalas del territorio de lo urbano.

En el Derecho a la ciudad habita un alto grado de optimismo respecto de las capacidades de la sociedad, fundamentalmente asentado en la clase obrera como sujeto activo que debía hacer efectivo el potencial de lo urbano dotándose de una estrategia. Tal posibilidad ha quedado aparentemente rota por la evolución social y el borrado de las categorías asociadas con el lugar ocupado en el proceso productivo. De alguna manera, y sólo pretendemos indicar una dirección, hemos pasado de las masas tumultuosas, donde era posible sentirse parte de un colectivo dotado de palabra, a la masa no congregada, que participa en programas generales. "Ahora se es masa sin ver a los otros" y las agrupaciones son involuntarias, forman parte de la dinámica de lo cotidiano (Sloterdijk, 2002). De modo que el horizonte real es la metáfora del desierto, la pérdida de las palabras y la profundización de los procesos de individuación.

Por el contrario, hay otras posiciones que aluden a un nuevo sujeto histórico: la multitud. Este es un concepto de larga historia, formulado contemporáneamente de tres formas diferentes: Paolo Virno (como ambivalencia, a modo de una ontología de la multitud), T. Negri y M. Hardt (la multitud instituyente: como virtualidad real) y $\mathrm{S}$. López Petit (la multitud de los derrotados/anónimos, con el potencial de la insurrección destituyente). Estas acepciones habitan en el seno de los nuevos movimientos sociales europeos y tienen un lugar decisivo en los recientes movimientos españoles. El potencial de conflicto en las metrópolis sigue ahí, ya sea estructural (las banlieus francesas), ya se 
manifieste intermitentemente (como los sucesivos brotes en las ciudades inglesas) o tenga una condición emergente (15-M español).

H. Lefebvre proponía una democracia ampliada, una reelaboración de las prácticas de la participación social, que implicaba tanto el espacio como su control y el derecho a la modificación de lo existente, incluyendo la creación artística colectiva. Por tanto, lo que planteaba no era exactamente una participación cualquiera sino la intervención, que no guarda relación directa ni con la democracia formal ni con la gobernanza. No explica sus contenidos con la suficiente amplitud pero su horizonte se resuelve "en otra escala, en otras condiciones, en otra sociedad" (Lefebvre, 1968, p. 125).

Cualquier concreción del derecho a la ciudad parece cristalizar más en las necesidades sociales, relegadas en la investigación, que en las individuales. El derecho a la ciudad implica el conocimiento de las necesidades sociales e, inevitablemente, la implementación de programas de investigación adecuados que no siempre serían coincidentes con los actuales, menos aún con los derivados de la proliferación de observatorios, indicadores e informes de "expertos", que no serían negados puesto que son útiles pero limitados. Tales investigaciones, que incluyen proposiciones y ensayos, requieren procesos temporales largos e incluyen temáticas que no interesan a las instituciones encargadas de definirlas y propiciarlas.

Lo que se nos impone es una nueva tarea: erigir un mundo desde/en el interior del existente. De todo ello, para lo urbano, se deduce un programa no escrito y unas oposiciones de las que podemos hablar concretamente pero que no son un programa de consignas a modo de una constelación de lo que debe ser hecho.

\section{Referencias}

AMENDOLA, Giandomenico. La ciudad postmo- derna. Madrid: Celeste Ediciones, 2000 (1997). AUGÉ, Marc. Los "no lugares". Espacios del anonimato. Barcelona: Gedisa, 1993 (1992).

AUGÉ, Marc. Hacia una antropología de los mundos contemporáneos. Barcelona: Gedisa, 1995 (1994).

AUGÉ, Marc. Anonimato y sobremodernidad. Espai en Blanc, 2010, $\mathrm{n}^{\circ}$ 5-6. $<$ http://www.espaienblanc.net/Anonimato-ysobremodernidad.html>. (Consultado el 16 de julio de 2011).

BECK, Ulrich \& SOPP, Peter (comps.). Individualisierung Und Integration. Munich: Opladen, 1997.

BECK, Ulrich. La sociedad del riesgo. Barcelona: Paidós, 1998 (1986).

BECK, Ulrich. La ciudad abierta. In BECK, U. La democracia y sus enemigos, Barcelona: Paidós, 2000, p. 115-124.

BECK, Ulrich. Vivir nuestra vida en un mundo desbocado: individuación, globalización y política. In GIDDENS, A. y HUTTON, W. (eds). En el límite. La vida en el capitalismo global. BarceIona: Tusquets, 2001, p. 233-245.

BÉGOUT, Bruce. Zerópolis. Barcelona: Anagrama, 2007 (2002).

BETTIN, Gianfranco. Los sociólogos de la ciudad. Barcelona: Gustavo Gili, 1982 (1979).

BOURDIE, Pierre. El sentido práctico. Madrid: Taurus, 1991 (1980).

CHALINE, Claude. La dinámica urbana. Madrid: Instituto de Estudios de la Administración Local, 1981.

COOKE, Philip. Modern urban theory in question. Transactions. Institute of British Geographers, 1990, n 15, p. 331-144.

CORCUFF, Philippe. Las nuevas sociologías. Madrid: Alianza, 1998 (1995).

DEBORD, Guy. Perspectivas de modificación consciente de la vida cotidiana, Internationale Situationiste, $1961, \mathrm{n}^{\circ} 6$. 
ELDEN, Stuart. Understanding Henri Lefebvre: theory and the possible. London/New-York: Continuum, 2004.

ELIAS, Norbert. El proceso de la civilización. Investigaciones sociogénicas y psicogénicas. México: Fondo de Cultura Económica, 1988 (1977 y 1979).

ELIAS, Norbert. La sociedad de los individuos. Barcelona: Península, 2000 (1987).

GOONEWARDENA, Kanishka; KIPFER, Stefan; MILGROM, Richard \& SCHMID, Christian (eds.). Space, Difference, Everyday Life: Reading Henri Lefebvre. Nueva York: Routledge, 2008.

GUTERMAN, Norbert et LEFEBVRE, Henry. La Conscience mystifiée. Paris: Gallimard, 1936.

HARVEY, David. Espacios de esperanza. Madrid: Akal, 2002 (2000).

HARVEY, David. El arte de la renta: la globalización y la mercantilización de la cultura. In HARVEY, D. y SMITH, N. (eds). Capital financiero, propiedad inmobiliaria y cultura. Barcelona: Museu d'Art Contemporani de Barcelona y Universitat Autònoma de Barcelona, 2005.

HARDT, Michael y NEGRI, Antonio. Multitud. Guerra y democracia en la era del Imperio. Barcelona: De Bolsillo, 2006 (2004).

HESS, Rémi. La méthode d'Henri Lefebvre. Multitudes, revue politique, artistique, philosophique, 2004.

<http://multitudes.samizdat.net/article.php3?id_ article=618>. (Consultado el 2 de mayo de 2008).

INGLEHART, Ronald. The silent revolution. Princenton: Princenton University Press, 1977.

INGLEHART, Ronald. Culture Shift in Avance Industrial Society. Princenton: Princenton University Press, 1990.

INGLEHART, Ronald. Modernización y postmodernización. Madrid: Centro de Investigaciones Sociológicas, 1999.
INNERARITY, Daniel. El futuro y sus enemigos. Una defensa de la esperanza política. Barcelona: Paidós, 2009.

KANAPA, Jean. Henri Lefebvre ou la philosophie vivante, La Pensée, 1947, n 15, p. 2.

LEFEBVRE, Henri. L'apport du marxisme á l'enseignement philosophique. Paris: La Pensé, 1947.

LEFEBVRE, Henri. Critique de la vie quotidienne. París: L'Arche, 1947.

LEFEBVRE, Henri. Autocritique. Contribution à l'effort d'eclaircissemente ideologique. La Nouvelle Critique, 1949, $\mathrm{n}^{\circ} 4$, p. 41-57.

LEFEBVRE, Henri. La somme et le reste. Paris: Le Nef de Paris, 1959.

LEFEBVRE, Henri. Le marxisme et la pensée française. Les Temps Modernes, 1958, n 137 138.

LEFEBVRE, Henri. Critique de la vie quotidienne. París: L'Arche, 1963.

LEFEBVRE, Henri. La vie quotidienne dans le monde moderne. Paris: Gallimard, 1968. (Traducción castellana: Madrid: Alianza editorial, 1972).

LEFEBVRE, Henri. Le droit á la ville. Paris: Antrhropos, 1968. (Traducción castellana: Barcelona: Península, 1969).

LEFEBVRE, Henri. La revolución urbana. Madrid: Alianza editorial, 1972 (1970).

LEFEBVRE, Henri. Le Manifieste Differentialiste. Paris: Gallimard, 1970.

LEFEBVRE, Henri. La présence et l'absence. Contribution à la théorie des représentations. Paris: Casterman, 1980. (Traducción castellana: México: Fondo de Cultura Económica, 1983).

LEFEBVRE, Henri. De la modernité du modernisme (Pour une métaphilosophie du quotidienne). Paris: L'Arché, 1981.

LEFEBVRE, Henri et REGULIER, Catherine. Le Project rythmanalitique. Comunications, 1985, $n^{\circ}$ 41, p. 191-199. 
LEFEBVRE, Henri y REGULIER, Catherine. Eléments de rythmanalyse: Introduction à la connaissance des rythmes. París: Syllepse, 1992.

LEFEBVRE, Henri. La production de l'espace. Paris: Anthropos, 1994.

FERIA, José $M^{a}$. Ciudad y territorio: nuevas dinámicas espaciales. In PUJADAS, I. et al. (Eds.): Población y Espacios urbanos, p. 13-52. BarceIona: Departament de Geografia Humana de la Universitat de Barcelona y Grupo de Población de la AGE, 2011.

LÓPEZ PETIT, Santiago. Más allá de la crítica de la vida cotidiana. Espai en Blanc, 2006, $\mathrm{n}^{\circ} \quad 1$ 2. <http://www.espaienblanc.net/Mas-alla-de-lacritica-de-la-vida.html>. (Consultado el 10 de agosto de 2011).

MERRIFIELD, Andy. Henri Lefebvre: A Critical Introduction. London: Routledge, 2006.

RUBIO DÍAZ, Alfredo. Dialéctica y estructuras en la comprensión marxista del espacio. In /I CoIoquio Ibérico de Geografía, 1980, Comunicaciones, vol. II, p. 113-122.

RUBIO DÍAZ, Alfredo. La ciudad actual como objeto de reflexión y análisis. In DOMíNGUEZ RODRÍGUEZ, R. (coord.). La ciudad. Tamaño y crecimiento. Málaga: Universidad de Málaga, Departamento de Geografía y Asociación de Geógrafos Españoles (AGE-Grupo de Geografía Urbana), 1999, p. 455-470.

RODRIGUEZ IBAÑEZ, José Enrique. Hacia un nuevo marco teórico (presentación). Revista de Occidente, 1993, n 150, p. 5-18.

RUBIO DÍAZ, Alfredo; REINOSO BELLIDO, Rafael y FERNÁNDEZ VALDERRAMA, Luz. Transformaciones en la relación entre lo doméstico y lo público. Neutra, 2008, nº 16, p. 52-57.

SLOTERDIJK, Peter. El desprecio de las masas. Ensayo sobre las luchas culturales en la sociedad moderna. Valencia: Pretextos, 2002 (2000).

SOJA, Edward W. Postmodern geographies: the reassertion of space in critical social theory. London: Verso Press, 1989.

SOJA, Edward W. Thirdspace. Journeys to Los Angeles and Other Real-and-Imagined Places. Oxford: Blackwell, 1996.

SOJA, Edward W. Postmetropolis: Critical Studies of Cities and Regions. Oxford: Blackwell, 2000. SOJA, Edward W. Seeking Spatial Justice. Minneapolis: University of Minnesota Press, 2010.

STANEK, Lukasz. Henri Lefebvre on Space: Architecture, Urban Research and the Production of Theory. Minneapolis: University of Minnesota Press, 2011.

STEWART, Lynn. Bodies, visions, and spatial politics: a review essay on Henri Lefebvre's The Production of Space. Society and Space, 1995, vol. 13(5), p. 609-618.

SUGRANYES, Ana. El derecho a la ciudad. Praxis de la utopia. Hábitat y Sociedad, 2010, n 1, p. 71-79. <www.us.es.habitatysociedad.es>. (Consultado el 12 de julio de 2011).

TIQQUN. Teoría del Bloom. Madrid: Melusina, 2005 (2000).

TIQQUN. Llamamiento y otros fogonazos. Madrid: Acuarela Libros, 2009 (2003).

TREBITSCH, Michel. Philosophie et marxisme dans les années trente: le marxisme critique d'Henri Lefebvre. Actes du Colloque 'L'engagement des intellectuels dans la France des années trente". 1990, CERAT, Université du Québec.

VIRNO, Paolo. General intellect, éxodo, multitud. Entrevista con Paolo Virno. Archipiélago, 2002, no 54, p. 104-117.

VIRNO, Paolo. Grammatica della moltitudine. Roma: Derive Approdi, 2.002.

ZARZA, Daniel. El sitio de las ciudades: elementos de un análisis territorial propositivo. Estudios Territoriales, 1985, nº 18, p. 167-180. 


\section{Cita del artículo}

RUBIO DÍAZ, Alfredo. Primeros elementos para una genealogía del derecho a la ciudad: $H$. Lefebvre. Hábitat y Sociedad, 2011, $\mathrm{n}^{\circ} 2$, p. 89-107. $<w w w . h a b i t a t y s o c i e d a d . u s . e s>$.

http://dx.doi.org/10.12795/HabitatySociedad.2011.i2.05 